\title{
Modern superconductive materials for electrical machines and devices working on the principle of levitation
}

\author{
T.A. Prikhna \\ Institute for Superhard Materials of the National Academy of Sciences of Ukraine \\ 2 Avtozavodskaya Str., Kiev, 04074, Ukraine \\ E-mail: prikhna@iptelecom.net.ua; prikhna@mail.ru
}

Received September 7, 2005

\begin{abstract}
The peculiarities of high-pressure synthesis of highly dense nanostructural $\mathrm{MgB}_{2}$-based superconductive materials, of thermobaric treatment of MT-YBCO (melt-textured $\mathrm{YBa}_{2} \mathrm{Cu}_{3} \mathrm{O}_{7-\delta^{-}}$ based superconductor), high-pressure sintering of $\mathrm{YBa}_{2} \mathrm{Cu}_{3} \mathrm{O}_{7-\delta}$, oxygenation of MT-YBCO under high isostatic pressure of oxygen and processes of formation of superconductive junctions between MT-YBCO blocks are considered. The attained level of superconductive and mechanical properties of such materials and junctions make them promising for application in cryogenic devices working on the principle of levitation: electricmotors, generators, pumps for liquid-gas transfer, magnetic bearings, flywheels, fault current limiters, maglev transport, etc. High-pressure synthesized $\mathrm{MgB}_{2}$ (with Ti additions) blocks were for the first time tried in the superconductive electricmotor at $20 \mathrm{~K}$ and demonstrated an efficiency similar to $\mathrm{MT}-\mathrm{YBCO}$ (at the same working temperature).
\end{abstract}

PACS: 74.72-h, 85.70.Rp

Keywords: high-pressure synthesis, sintering and treatment, superconductive junction, cryogenic device.

\section{Introduction}

The speedy development of high temperature superconductivity that took place during last 20 years leads to the creation of new bulk superconductive materials that are successfully used in cryogenic electricmotors, generators, pumps for liquid-gas transfer, magnetic bearings, flywheels, fault current limiters, maglev transport and other devices working on the principal of levitation. At present the most promising materials from the point of view of critical current density and ability to accumulate magnetic energy (level of trapped magnetic field) are $\mathrm{YBa}_{2} \mathrm{Cu}_{3} \mathrm{O}_{7-\delta}$-based melt textured ceramics (MT-YBCO) with a working temperature of about $77 \mathrm{~K}$. Recently (in 2001) the superconductive properties of $\mathrm{MgB}_{2}$ were found. This compound occupies an intermediate place between the high-temperature and low-temperature superconductors because of the transition temperature $(39-40 \mathrm{~K})$, but beyond type-II superconductors. Despite the comparatively low transition temperature, interest in the $\mathrm{MgB}_{2}$-based materials can be explained on one hand by the simpler and cheaper preparation technique (than in the case of HTSC) and on the other by the intensive development of technologies that use liquid hydrogen as an alternative fuel for automobile, water and aviation transport and for transmission of electrical energy on long distances. It should be mentioned that the boiling temperature of liquid hydrogen $(20 \mathrm{~K})$ is the working temperature for the $\mathrm{MgB}_{2}$-based superconductive materials.

The present paper deals with investigation of high-pressure synthesis of highly-dense $\mathrm{MgB}_{2}$-based nanostructural superconductive materials, with the thermobaric treatment of MT-YBCO and with the study of the formation of superconductive junctions between MT-YBCO blocks in order to increase the efficiency of the use of these materials in cryogenic machines and devices, in particular in superconductive (SC) electricmotors and pumps.

The superconductive electricmotors are remarkable for high energy density on the rotor surface and because of this are approximately 7-10 times more compact and lighter than the traditional ones. This creates auspicious conditions for saving space and weight, 
which is extremely important when SC motor or pumps are used in transport (especially if liquid nitrogen or hydrogen is already present on the vehicle to provide for of some other processes). A decrease of rotor sizes leads to a decrease of the inertial moment of the motor that is of great importance for the case of work in the regime of often reverse (for example to guide looms or stamping presses, special stands for automobile testing etc.). It has turned out that the most efficient use of the bulk superconductors is in the reluctance-type motors [1]. High critical current density and a high level of trapped magnetic field are among the requirements for SC materials, i.e., the high level of magnetic energy that the material can accumulate, and the high mechanical characteristics, because the superconductive material is permanently subjected to the essential stresses: exerted by the magnetic field and by thermal strains as a result of thermo-cycling from room temperature down to the working temperatures.

Production technologies of superconductive materials based on $\mathrm{YBa}_{2} \mathrm{Cu}_{3} \mathrm{O}_{7-\delta}$ (or Y123) and $\mathrm{MgB}_{2}$ with high critical currents are quite different because of the difference in the coherence length of the compounds: $0.6-3.1 \mathrm{~nm}$ for Y123 [2] and 1.6-12 $\mathrm{nm}$ for $\mathrm{MgB}_{2}$ [3]. The coherence length in type-II the superconductors, as a rule, is determined by the size of the defects or inclusions that can be pinning centers of the magnetic flux and thus can promote an increase in critical current density of the material. Because of this, in the Y123-based superconductors the grain boundaries with the high off-orientation angles are a significant obstacle for the superconductive current flow, and their presence in the material leads to a substantial decrease of critical current density, $j_{c}$, and the pinning centers in the material can be dislocations, stacking faults, and twins [4]. In order to get higher critical current densities, the MT-YBCO ceramics are grown, where the high $j_{c}$ is attained due to the textured structure growing with the help of seed crystal. Practically the Y123 single-crystal structure is growing in throughout the whole bulk of the sample, and in such a structure the inclusions of the nonsuperconductive, so-called «green» $\mathrm{Y}_{2} \mathrm{BaCuO}_{5}$ (Y211) phase in the amount of $25-30 \mathrm{wt} \%$ are finely dispersed. The presence of the nonsuperconductive dispersed inclusions of the Y211 phase in the superconductive structure improves the pinning due to the formation of high-density of dislocations and stacking faults around the Y211 grains. The structure formation of the MT-YBCO sample measuring $70 \times 70 \times 40 \mathrm{~mm}$ takes two weeks and two more weeks are necessary to saturate the sample with oxygen in order to impart the superconductive properties to it. It should be mentioned that at the last stage (oxygenation) a large amount of macro and micro cracks are forming in the samples. Sometimes the samples exhibit rather big pores. The batch production (about 30 pieces in one run) makes the material cheaper and the price

\section{Recessed-anvil-type}

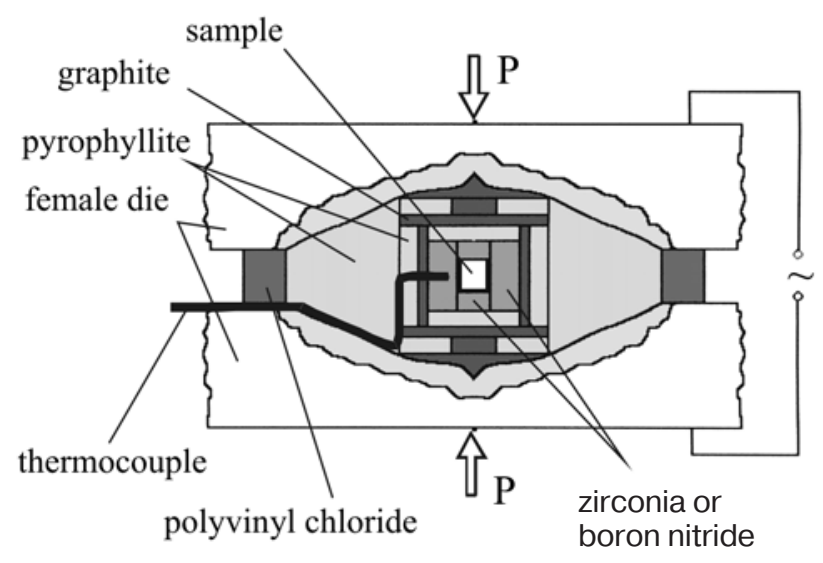

Cube type

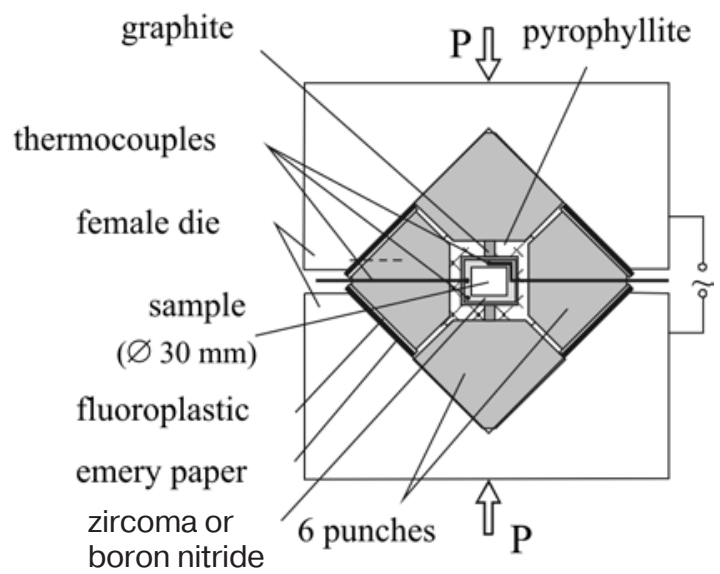

Scheme of the load distribution
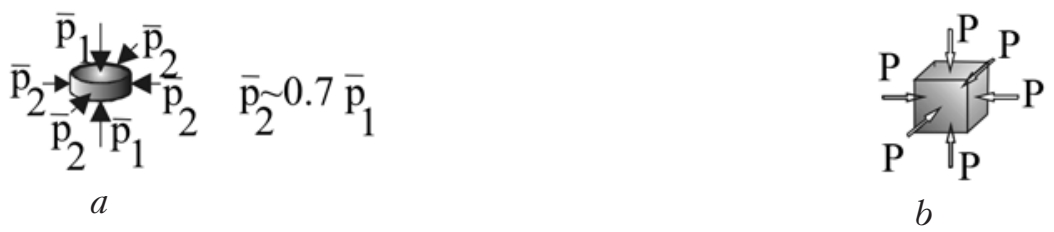

Fig. 1. High-pressure apparatuses (HPA) of a recessed anvil ( $a$ ) and cube (b) types and schemes of the load distribution in the HPA. The shown arrangement is suitable for treatment, sintering or synthesis of SC materials. 
for $1 \mathrm{~kg}$ of laboratory produced MT-YBCO is about 2000 EUR.

The higher coherence length of $\mathrm{MgB}_{2}$ gives the possibility to attain high critical current densities in the polycrystalline material structure, because the grain boundaries are smaller than the coherence length and are not obstacles for superconductive current flow. The pinning centers in $\mathrm{MgB}_{2}$ can be nanosized inclusions of the second phase, and chemical alloying for example, can increase the critical current density of the material. At the Institute for Superhard Materials a method of high-pressure high-temperature synthesis of highly dense nanostructural $\mathrm{MgB}_{2}$-based material with the highest (among known from literature) values of critical current density in magnetic field and mechanical characteristics has been developed [5]. The availability of the high-pressure apparatus with a working volume of about $100 \mathrm{~cm}^{3}$ makes it possible to produce blocks from the developed material with sizes suitable for application in superconductive electricmotors and pumps for liquid hydrogen transfer.

\section{Experimental}

For thermobaric or high-pressure-high-temperature (HP-HT) treatment, sintering and synthesis, a recessed-anvil and cube-type high-pressure apparatus (HPA) with a working volume up to $100 \mathrm{~cm}^{3}$ (Fig. 1) are used to create a pressure of $2-5 \mathrm{GPa}$ and a temperature of $750-1400^{\circ} \mathrm{C}$. As we have shown, on heating at high pressure, compacted monoclinic zirconia powder can prevent losses of oxygen from the $\mathrm{ReBa}_{2} \mathrm{Cu}_{3} \mathrm{O}_{7-\delta}$ (Re123) structure, where Re is $\mathrm{Y}, \mathrm{Nd}, \mathrm{Gd}, \mathrm{Sm}, \mathrm{Eu}$, or even promote an increase of oxygen content of the structure, so during HP-HT treatment Y123-based materials were in contact with $\mathrm{ZrO}_{2}$. The synthesis of $\mathrm{MgB}_{2}$-based materials was conducted in contact with compacted hexagonal $\mathrm{BN}$ powder.

The oxygenation under isostatic oxygen pressure was performed in a cylindrical stainless steel apparatus (gasostat), which can be filled with oxygen up to a pressure of $16 \mathrm{MPa}$ and heated at this pressure up to $800^{\circ} \mathrm{C}$. The oxygenation was performed by the following regime: heating from 20 to $700^{\circ} \mathrm{C}$ at a rate of $46^{\circ}$ per hour, the nitrogen atmosphere (1 bar pressure) was replaced by the oxygen one (the gases flowing through the gasostat) in accordance with an exponential law. When the temperature was increasing up to $700^{\circ} \mathrm{C}$, the samples were in the pure oxygen atmosphere (under 1 bar pressure). Then keeping the temperature at about $700^{\circ} \mathrm{C}$, we increased the oxygen pressure according to the exponential law up to 16 $\mathrm{MPa}$, at these conditions the samples were held for $20 \mathrm{~h}$ and the heating was switched off and the samples cooled down «with the furnace» to room temperature.
All in all, the samples were held at $700^{\circ} \mathrm{C}$ for 60 hours. Such a complicated procedure of the so-called progressing oxygenation was chosen to reduce cracking (to obtain the material with high $j_{c}$ ) by keeping oxygen content of the Y123 phase in the equilibrium respectively to the oxygen pressure in the surrounding atmosphere under each temperature.

The characteristics of raw materials and method of preparation of the initial samples will be given in the paragraphs connected with each of the describing technique.

The structure of materials has been studied using a polarized optical microscope, SEM and TEM (at $200 \mathrm{kV}$ ) as well as $\mathrm{x}$-ray structural and phase analyses. It is well known that in the range of $0 \leq \delta \leq 1$ for the $\mathrm{YBa}_{2} \mathrm{Cu}_{3} \mathrm{O}_{7-\delta}$ phase, there exists a linear dependence between the $c$-parameter and oxygen content of the phase. We have calculated $\delta$ by the established equation $\delta=60.975, c-71.134$. The sample density $\gamma$ was determined by hydrostatic weighing. The $j_{c}$ was estimated from magnetization hysteresis loops obtained on an Oxford Instruments 3001 vibrating sample magnetometer (VSM) using Bean's model. For VSM measurements, samples with a typical diameter of $3 \mathrm{~mm}$ were prepared and this size was applied to calculate the $j_{c}$ values.

The trapped magnetic field distribution over the field-cooled samples was found using the Hall probe (the distance from the Hall probe to the sample surface was $0.8 \mathrm{~mm}$ ). The magneto-optical study has been performed using the magneto-optical microscope.

Hardness was measured employing a Matsuzawa Mod. MXT-70 microhardness tester, $H_{V}$ (using a Vickers indenter) and Berkovich Nano-indenter II, $H_{B}$ (using a Berkovich indenter). The Vickers microhardness was estimated under a load of $1.96 \mathrm{~N}$ and can give a notion about mechanical properties of the material as a whole. The Berkovich nanohardness was measured under a very low load of $0.05 \mathrm{~N}$. It allowed us to estimate hardness even of small inclusions. In the case when we investigated starting melt-textured ceramics, we have made measurements in the pore-free places. So, determining the Berkovich nanohardness we can estimate the maximal hardness of the material. It should be taken into consideration that with a decrease in the indentation load, the hardness increases. The fracture toughness was estimated from the length of the radial cracks emanating from the corners of an indent using equation [6]: $K_{1 c}=0,0725 P / c^{1,5}$, where $P$ is the indentation load and $c$ is the length of a radial crack emanated from the corner of the indent.

SIMS chemical analysis was carried out using a Cameca NanoSIMS 50 with a $\mathrm{Cs}^{+}$primary ion beam. The particular importance of the NanoSIMS in this 
study is its ability to map the hydrogen distribution throughout the samples. Electron microprobe analysis (EPMA) was performed on the samples using a JEOL JXA 8800 Superprobe.

\section{High pressure-high temperature treatment and sintering of Y123-based superconductors, oxy- genation of MT-YBCO under isostatic pressure}

As starting samples, we used (1) $\mathrm{YBa}_{2} \mathrm{Cu}_{3} \mathrm{O}_{7-\delta}$ $(\delta \approx 0)$ precompacted powder of a low residual carbon content (with a fraction of total mass of carbonates $\left.\left(\mathrm{CO}_{3}\right)^{2-} \leq 0.3 \mathrm{wt} \%\right)$ for HP-HT sintering experiments; (2) melt-textured $\mathrm{YBa}_{2} \mathrm{Cu}_{3} \mathrm{O}_{7-\delta}$-based ceramics (so-called MT-YBCO): $(2 a)$ with $\delta \approx 0$ (superconductive) for HP-HT treatment and (2b) with $\delta \approx 0.7$ (nonsuperconductive) for oxygenation experiments under isostatic pressure; (3) melt-textured $\mathrm{YBa}_{2} \mathrm{Cu}_{3} \mathrm{O}_{7-\delta}$-based superconductive ceramics with $14 \mathrm{wt} \%$ addition of Ag that was added in order to reduce porosity and to increase mechanical characteristics of the material (so-called MT-YBCO-Ag), for HP-HT treatment. It should be noted that for oxygenation process the rectangular bars were cut from single domain MT-YBCO blocks that were textured under low oxygen pressure $(\leq 5 \mathrm{mbar})$ in nitrogen atmosphere and thus free of cracks.

Figures 2, $a$ and $2, b$ show variations of the unit cell parameters of the Y123 phase of ceramics HP-HT sintered from Y123 powder and of HP-HT-treated MT-YBCO. Under 2-5 GPa the orthorhombic Y123 phase is stable up to $1100^{\circ} \mathrm{C}$, while under the ambient pressure it starts to transform into tetragonal one at about $400{ }^{\circ} \mathrm{C}$ (due to the oxygen liberation from basal $\mathrm{CuO}_{1}$ planes) and at about $980-1000{ }^{\circ} \mathrm{C}$ the $\mathrm{Y} 123$ structure decomposes. When oxygen liberates from $\mathrm{YBa}_{2} \mathrm{Cu}_{3} \mathrm{O}_{7-\delta}$, the $c$-parameter increases and the amount of oxygen in the range of $0 \leq \delta \leq 1$, can be determined using the existing linear dependence between the oxygen content and the $c$-lattice parameter. An increase of treatment or sintering temperature (higher than $1100^{\circ} \mathrm{C}$ ) under HP leads to the decrease of the $c$-parameter, transformation of the structure into the tetragonal and then pseudocubic one with $a=b=c / 3$. Such a behavior, as was shown by us earlier [7], is connected with the increase in oxygen content up to more than 7 oxygen atoms per one Y123 unit cell and results in loosing of SC properties. Even after sintering at $1500^{\circ} \mathrm{C}$ the residues of Y123 structure were observed. But it's impossible to relate $c$ to $\delta$ for $\delta>1$ because the samples were multiphase. In spite of the fact that sintering of Y123 above $1100^{\circ} \mathrm{C}$ (at $5 \mathrm{GPa}$ ) causes the structure to start to transform into the tetragonal one (Fig. 2,a), the $j_{c}$ value is still high even at $1400^{\circ} \mathrm{C}$ (Fig. 3). May be the supersaturated-with-oxygen phase
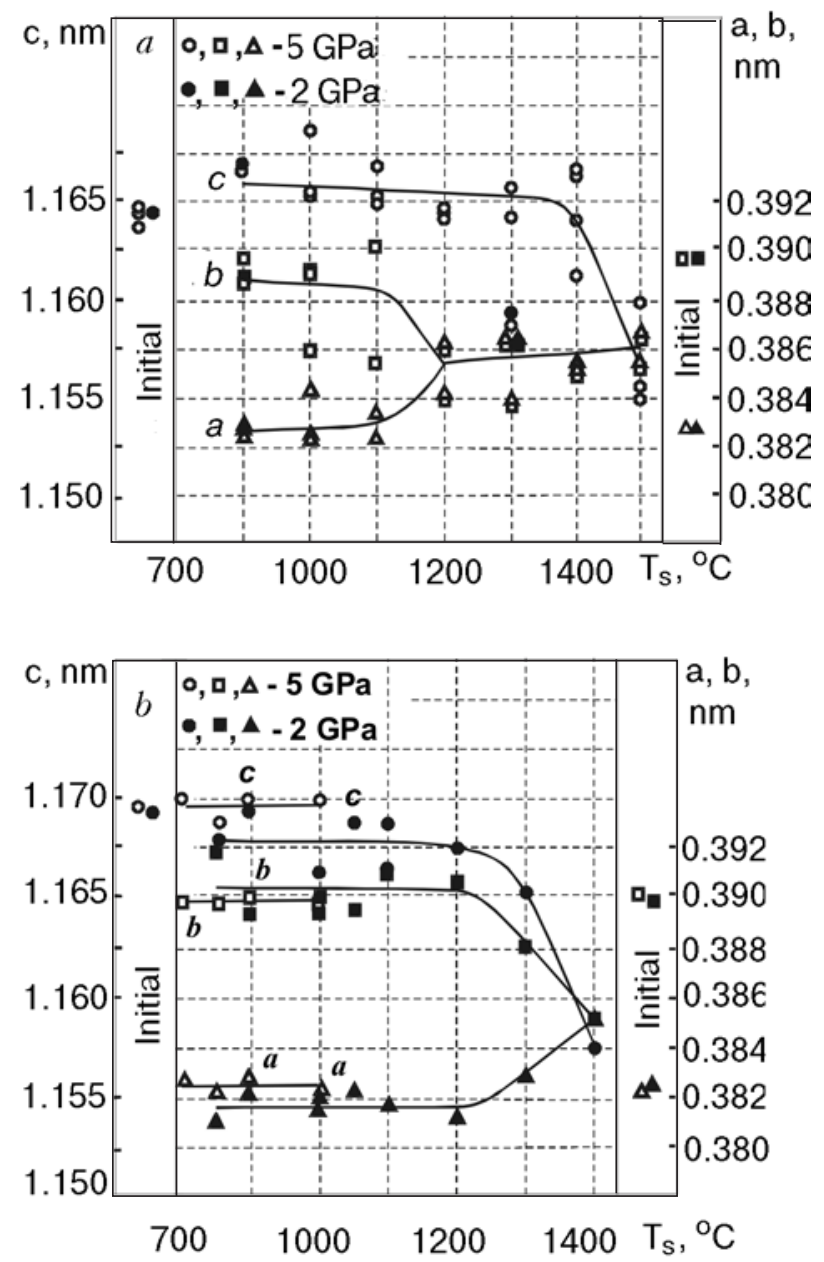

Fig. 2. Unit cell parameters $a, b, c$ : (a) of Y123 initial powder and Y123 ceramics sintered under 2 and $5 \mathrm{GPa}$ vs. treatment temperature, $T_{s}$; $(b)$ of Y123 phase of MT-YBCO before and after treatment under 2 and $5 \mathrm{GPa}$ vs. treatment temperature, $T_{s}$.

(tetragonal) uniformly dispersed throughout orthorhombic Y123, serves as pinning centers and gives the averaged tetragonal $\mathrm{x}$-ray picture. Sometimes we have detected two phases with «normal» $(\delta \geq 0)$ and «reduced» $(\delta<0) c$-parameters in the same sample. It is important to use for HP sintering a low residual carbon powder, because for higher amounts (for example, $0.7 \mathrm{wt} \%$ of $\mathrm{CO}_{3}^{2-}$ ), the decomposition of $\mathrm{Y} 123$ occurs under much lower temperatures (at about $900^{\circ} \mathrm{C}$ ).

It is well known that superconducting characteristics of Y123-based ceramics such as critical current density and the field of irreversibility depend on structural defects (oxygen vacancies, dislocations, stacking faults, micro- and macrocracks, etc.). Generally during the oxygenation, the transformation of tetragonal Y123 phase into orthorhombic brings about the formation of twins, micro- and macrocracks, dislocations, stacking faults in the MT-YBCO structure. High pressure-high temperature treatment is a power- 


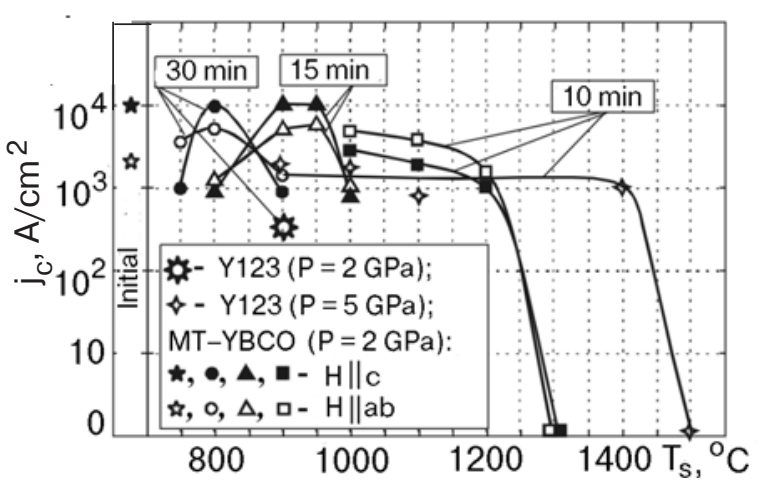

Fig. 3. Critical current density in zero magnetic field at $77 \mathrm{~K}$ : of Y123 powder and Y123 ceramics sintered under 2 and $5 \mathrm{GPa}$, of MT-YBCO before and after HP-HT treatment under $2 \mathrm{GPa}$ in the $a b$ plane $(\mathbf{H} \| c)$ and in perpendicular direction $(\mathbf{H} \| a b)$.

ful instrument to change the structure and properties of MT-YBCO $[8,9]$.

The density, microhardness, fracture toughness and superconductive characteristics of the HP-HT-treated melt-textured MT-YBCO material can be improved ( $\mathrm{Ta}-$ ble 1, Figs. 3, 4). For example, for the MT-YBCO-Ag samples (with $14 \mathrm{~mol} \%$ of $\mathrm{Ag}$ added), we observed a 1.6-1.8 time increase in critical current density in zero and low magnetic fields (up to $2 \mathrm{~T}$ ) after treatment at $850^{\circ} \mathrm{C}$ and $2 \mathrm{GPa}$ for $15 \mathrm{~min}$ as compared to the starting sample (Fig. 4). After HP-HT treatment the homogenization of the sample structure was observed (Fig. 5). In the melt-textured samples without additions of $\mathrm{Ag}$, after HP-HT treatment, a decrease of anisotropy of the critical current density due to the increase in the critical current in the direction of the $c$-axis of Y123 has been found. We believe that the increase in the critical current density, $j_{c}$, (when $\mathrm{H} \| a b$ ) is due to the increase in the dislocation density from $10^{8}$ up to $10^{12} \mathrm{~cm}^{-2}$ in the (001) planes of Y123 as demonstrated by the TEM study of MT-YBCO (Fig. 6) [10]. The increase of the material density (Table 1) can also contribute to the $j_{c}$ increase. Because the stresses that usually act in the vertical and radial directions in the recessed-anvil

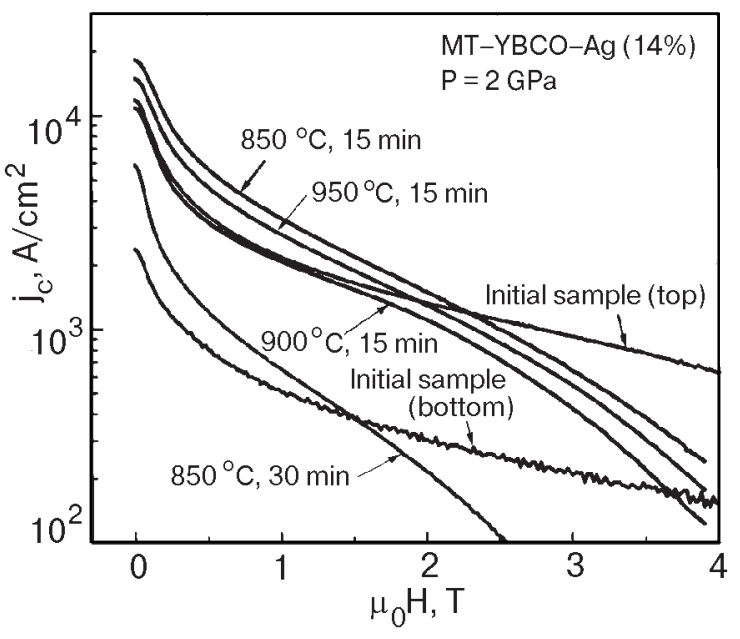

Fig. 4. Critical current density, $j_{c}$, vs. magnetic field, $\mu_{0} H$, ( $\mathbf{H} \| a b$-plane of Y123) at $77 \mathrm{~K}$ for MT-YBCO-Ag before and after HP-HT treatment.

high-pressure apparatus differ by about $30 \%$, we can change the density of defects, e.g. twins and dislocations, by changing the orientation or position of a treated sample (matrix of $\mathrm{MT}-\mathrm{YBCO}$ is practically a single domain of Y123).

Figure 7 show the dependences of critical current density vs. magnetic field of MT-YBCO HP-HT -treated (untwinned) and oxygenated under isostatic oxygen pressure, the so-called progressive oxygenation. The MT-YBCO ceramics progressively oxygenated at $16 \mathrm{MPa}$ exhibited very high critical current density in both directions at $77 \mathrm{~K}$ : when the external magnetic field was perpendicular to the $a b$-plane of Y123, we observed the $j_{c}=85 \mathrm{kA} / \mathrm{cm}^{2}$ in zero field and more than $10 \mathrm{kA} / \mathrm{cm}^{2}$ up to $5 \mathrm{~T}$ field, when magnetic field was perpendicular to the $c$-axis of $\mathrm{Y} 123$, we observed $j_{c}=23 \mathrm{kA} / \mathrm{cm}^{2}$ in zero field and $j_{c}=1 \mathrm{kA} / \mathrm{cm}^{2}$ in $8 \mathrm{~T}$ field (see Fig. $7, a$ ). The material structure is characterized by a comparatively low density of macrocracks parallel to the $a b$-plane of $5.3 \mathrm{~mm}^{-1}$; high density of microcracks parallel to the $a b$-plane of $0,5 \mu^{-1}$ and density of twins of $30 \mu^{-1}$ (Fig. 8,c) [11]. The density of stacking faults around Y211 inclusions was high

Table 1. Microhardness $H_{V}$, fracture toughness $K_{1 c}$, Young modulus $E$ and density $\gamma$ before and after HP-HT treatment of $\mathrm{MT}-\mathrm{YBCO}\left(\right.$ at $2 \mathrm{GPa}, 800{ }^{\circ} \mathrm{C}$ for $30 \mathrm{~min}$ ) and $\mathrm{MT}-\mathrm{YBCO}-\mathrm{Ag}$ (at $2 \mathrm{GPa}, 850{ }^{\circ} \mathrm{C}, 15 \mathrm{~min}$ )

\begin{tabular}{|c|c|c|c|c|c|c|c|c|}
\hline \multirow{2}{*}{ Material } & \multicolumn{2}{|c|}{$\begin{array}{c}H_{V}, \text { GPa under a } \\
\text { load of } 1.96 \mathrm{~N}\end{array}$} & \multicolumn{2}{|c|}{$\begin{array}{c}K_{1 c}, \mathrm{MN} \cdot \mathrm{m}^{-3 / 2} \\
\text { under the } 4.9 \mathrm{~N}-\mathrm{load}\end{array}$} & \multicolumn{2}{|c|}{$E$, GPa under the $0.05 \mathrm{~N}$-load } & \multicolumn{2}{|c|}{$\gamma, \mathrm{g} / \mathrm{cm}^{3}$} \\
\hline & before & after & before & after & before & after & before & after \\
\hline MT-YBCO & $4.89 \pm 1.81$ & $6.74 \pm 0.80$ & $0.70-1.5$ & No cracks & $10-180$ & 195 & 5.76 & 6.33 \\
\hline MT-YBCO-Ag & $4.96 \pm 1.09$ & $5.21 \pm 0.75$ & $0.78 \pm 0.13$ & $1.3 \pm 0.15$ & - & - & 6.5 & 6.9 \\
\hline
\end{tabular}




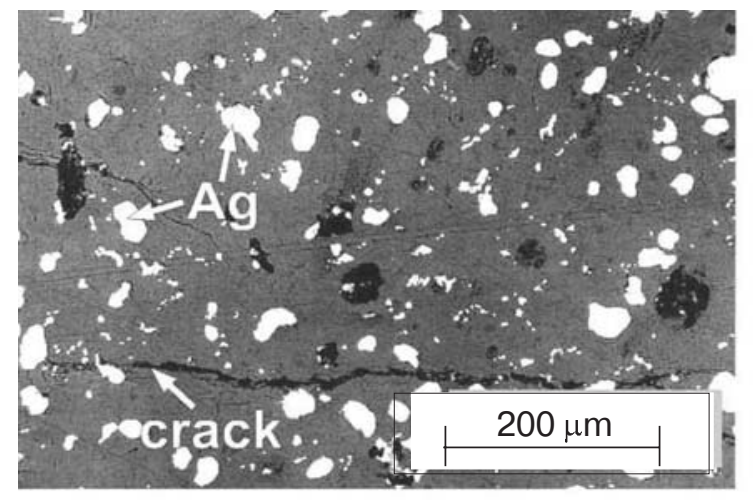

$a$

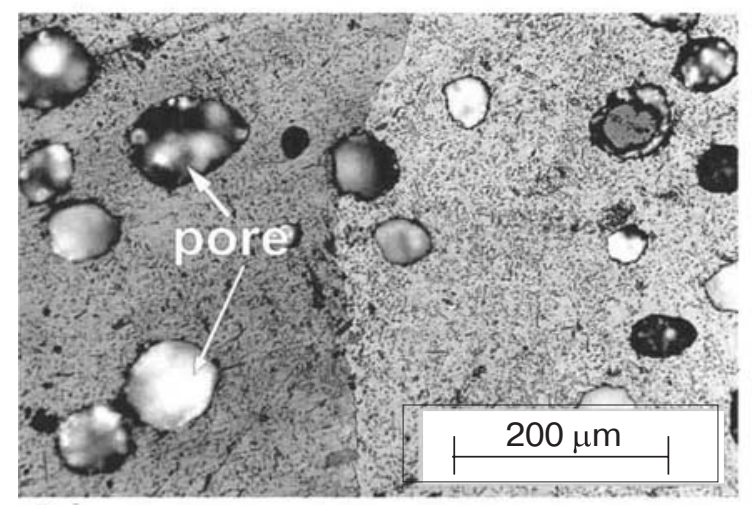

$b$

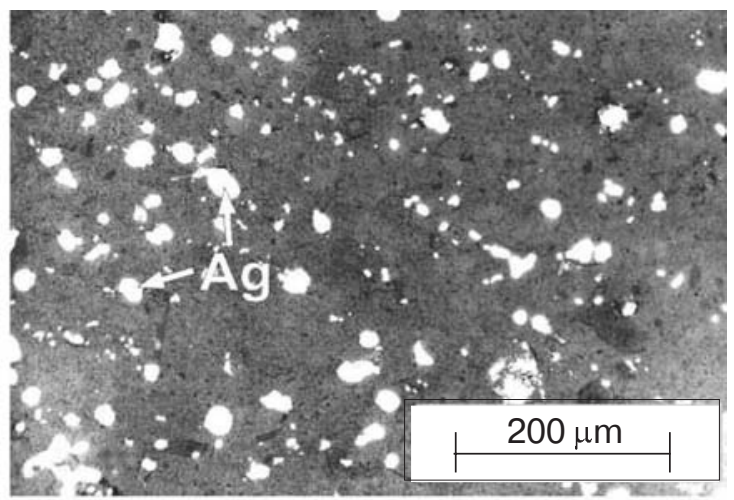

C

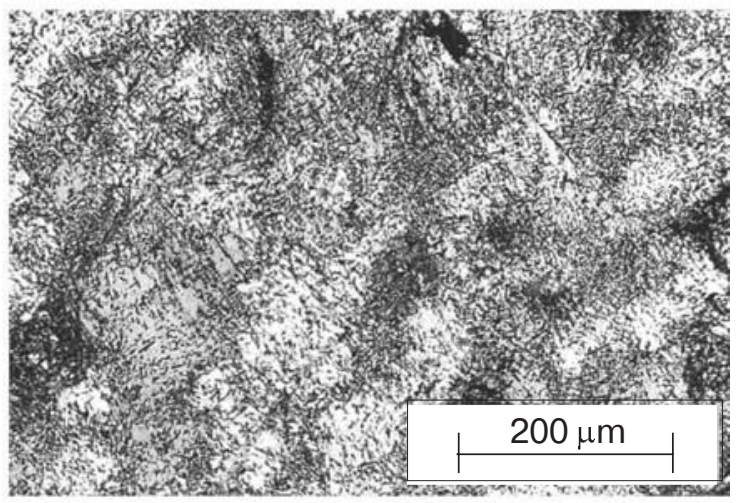

$d$

Fig. 5. Structure of melt-textured ceramics before and after HP-HT treatment: starting MT-YBCO-Ag $(a) \mathrm{MT}-(\mathrm{Nd}, \mathrm{Y}) \mathrm{BCO}$ (b), and MT-YBCO-Ag treated at $2 \mathrm{GPa}, 900{ }^{\circ} \mathrm{C}$ for $15 \mathrm{~min}(c)$, MT- $\left.\mathrm{Nd}, \mathrm{Y}\right) \mathrm{BCO}$ treated at $5 \mathrm{GPa}, 850{ }^{\circ} \mathrm{C}$ for $15 \mathrm{~min}(d)$.

as well. The lattice parameters of the Y123 matrix phase of $\mathrm{MT}-\mathrm{YBCO}$ before progressive oxygenation were $a=0.38589(3) \mathrm{nm}, \quad c=1.1828(1) \mathrm{nm}$ and after it

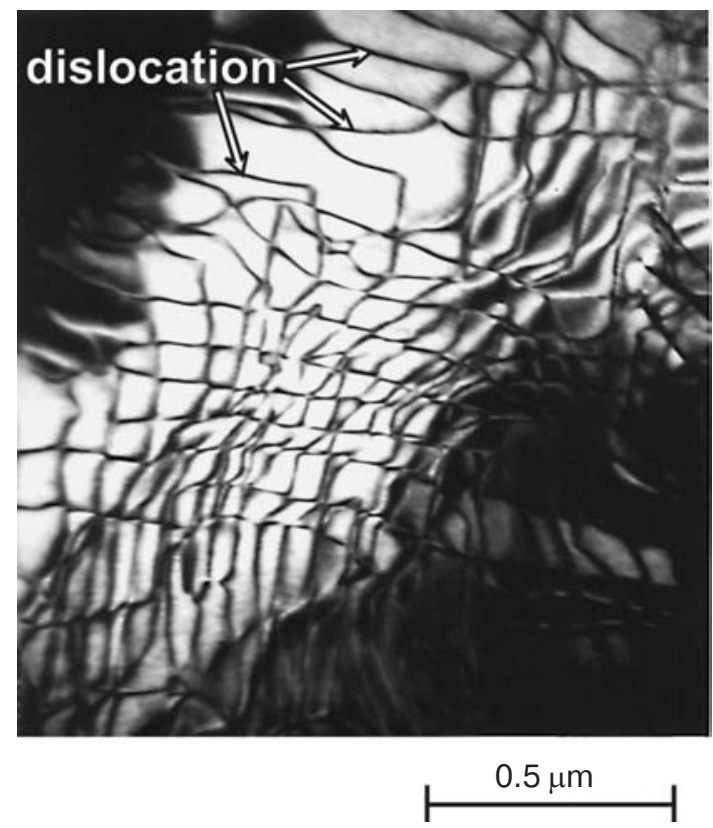

Fig. 6. TEM image showing a wide region with the high density of dislocations lying on the (001) plane of Y123 in MT-YBCO (treated at $2 \mathrm{GPa}, 900{ }^{\circ} \mathrm{C}, 15 \mathrm{~min}$ ). $a=0.38216(5) \mathrm{nm}, b=0.38828(6) \mathrm{nm}, c=1.1697(2)$ $\mathrm{nm}$. This is indicative of the fact that the oxygen content of $\mathrm{YBa}_{2} \mathrm{Cu}_{3} \mathrm{O}_{7-\delta}$ phase was about 7 atoms per one unit cell $(\delta \approx 0)$. The oxygen content of HP-HT treated samples was not changed (before treatment $a=0.3823 \mathrm{~nm}$, $b=0.3899 \mathrm{~nm}, \quad c=1.1688 \mathrm{~nm}$ and after treatment at $2 \mathrm{GPa}, 800{ }^{\circ} \mathrm{C}$ for $30 \mathrm{~min} a=0.3821 \mathrm{~nm}, \quad b=$ $=0.3895 \mathrm{~nm}, c=1.1687 \mathrm{~nm}$ ). HP-HT treated (specially untwinned) structure of MT-YBCO contained a low twin density of less than $2 \mu^{-1}$ (Fig. $8 a, b$ ). In the sample structure unusual perfect dislocations stepped along the $\langle 110\rangle$ directions were observed. The dislocation steps seem to be the «memory» of the vanished twins (Fig. 8,a). Small faulted loops (Fig. 8,b) corresponded to $\mathrm{CuO}$ intercalating in the matrix. In MT-YBCO oxygenated at elevated pressure, the difference between the critical current densities in zero field for the cases that $\mathbf{H}$ is parallel and perpendicular to the $a b$-plane is higher than that for HP-HT treated, while the absolute value of the critical current in zero field in the case that $\mathbf{H}$ is perpendicular to the $a b$-plane of the oxygenated sample is approximately one order of magnitude higher than of HP-HT treated. It seems that for high critical currents (higher than $10 \mathrm{kA}$ in zero magnetic field) the 

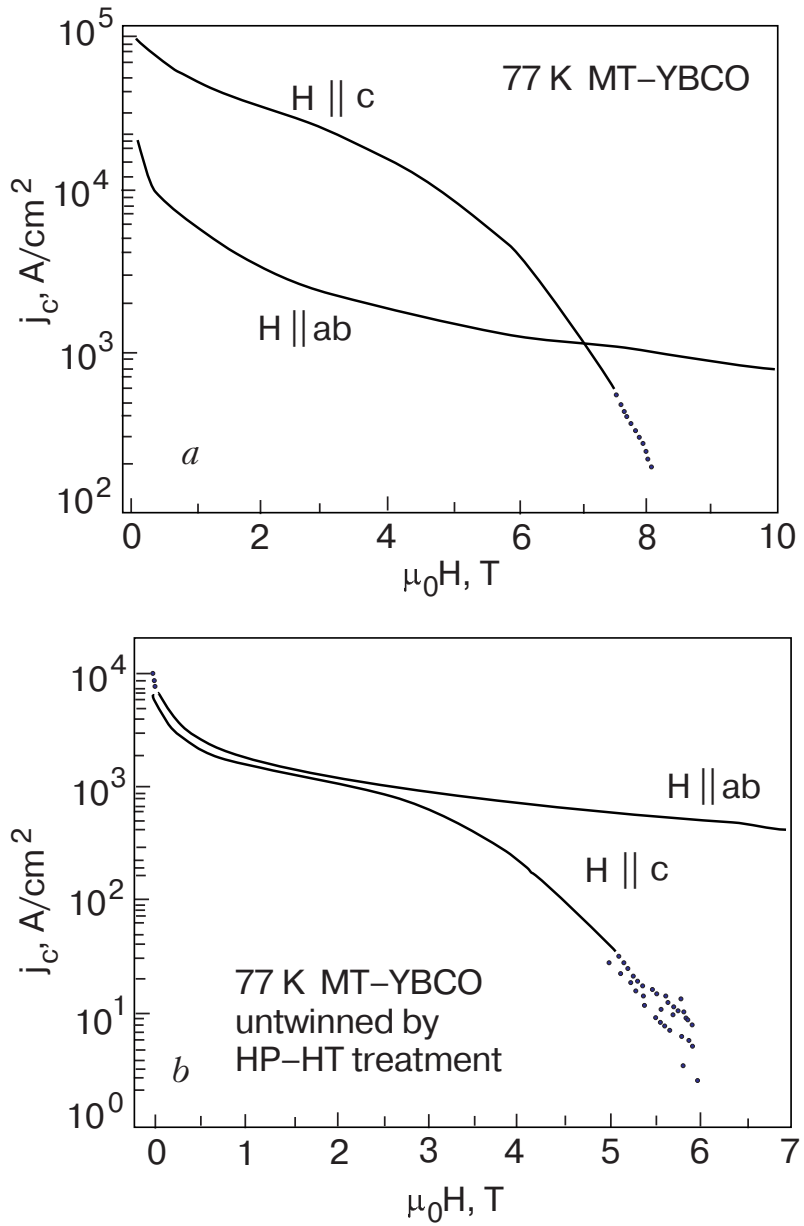

Fig. 7. Critical current density $j_{c}$ vs. magnetic field $\mu_{0} H, \mathrm{~T}$ at $77 \mathrm{~K}$ obtained using VSM for the cases that external magnetic field was perpendicular $(H \| c)$ and parallel $(H \| a b)$ to $a b$-plane of Y123 for: (a) MT-YBCO oxygenated at a pressure of $16 \mathrm{MPa}$; $b$ ) MT-YBCO untwined by $\mathrm{HP}-\mathrm{HT}$ treatment under $2 \mathrm{GPa}$.

important role is played by the twin density in the Y123 structure.

\section{Formation of superconducting junctions be- tween MT-YBCO blocks}

The quality of $\mathrm{MT}-\mathrm{YBCO}$ is determined by the maximal magnetic field that can be trapped in the ceramic material. The value of trapped field first of all depends upon the size of magnetic (in our case superconductive) domains. The size of domains is determined by the conditions of texture growth. The modern technologies allow one to grow high quality samples with linear dimensions not larger than 40-70 $\mathrm{mm}$. The demand for manufacturing larger products and with complicated configurations motivates the necessity for superconducting junctions between MT-YBCO blocks.

The investigation of the peculiarities formation of the superconductive junction between $\mathrm{MT}-\mathrm{YBCO}$ blocks and the complex study of correlations between the structure, superconductive and mechanical characteristics resulted in the development of a method of preparation of junctions with a stable level of properties: with critical current density higher than $10 \mathrm{kA} / \mathrm{cm}^{2}$ at $77 \mathrm{~K}$ in the magnetic fields up to $1.8 \mathrm{~T}$, microhardness $H_{V}=4.6 \mathrm{GPa}$ under the $1.96 \mathrm{~N}$-load and a bending strength of 28-32 MPa, when the powdered $\mathrm{TmBa}_{2} \mathrm{Cu}_{3} \mathrm{O}_{7-\delta}(\mathrm{Tm} 123)$ is used as solder. The Tm123 is isostuctural analog of superconductive matrix phase $\mathrm{YBa}_{2} \mathrm{Cu}_{3} \mathrm{O}_{7-\delta}$ (Y123) of $\mathrm{MT}-\mathrm{YBCO}$ and has practically the same transition superconductive temperature $(94 \mathrm{~K})$, but its incongruent melting temperature is lower by 30 degrees. The superconductive and mechanical properties (Fig. 9) of the junction and the sample as a whole do not yield to the respective properties of the initial MT-YBCO ceramic material (Patents $[12,13]$ ).

In order to estimate superconductive characteristics of the superconductive junctions original methods of critical current density estimation have been elaborated [14]: based on the measurement of trapped-field distribution by Hall probe; on the measurement of local levitation force (Patent [15]) and by complex estimation of critical current density in the rings from MT-YBCO using VSM, optical magnetometry and data of trapped magnetic field distribution.

The developed method of superconducting junction formation consists in the following. The powdered Tm123 solder is sieved or precipitated from suspension in acetone by thin layer $(0.3-0.5 \mathrm{~mm})$ onto the surfaces of ceramic blocks being joined. The forces of the electrostatic interaction give no possibility of powdered solder to be fallen down from the surfaces of blocks to be joined, so prepared in such a style blocks with solder can be rotated under any angle. Then the prepared surfaces are joined together, fixed in the special device and heated in a chamber furnace in oxygen atmosphere, where the formation of superconducting junction occurs. The fixing device allows the clamping pressure up to $200 \mathrm{kPa}$ to be created and the force of clamping can be regulated on the outside of the furnace during the process of junction formation up to $1100{ }^{\circ} \mathrm{C}$ in the atmosphere of oxygen.

The following general peculiarities of the formation of superconducting junction between $\mathrm{MT}-\mathrm{YBCO}$ blocks have been established. The maximal temperature of the junction with high level of superconductive characteristics lies between $990-1010{ }^{\circ} \mathrm{C}$; it is better to form the junction in the oxygen atmosphere; the holding time at the maximal temperature should not exceed 7-30 min. When the sample is heated to a temperature higher than $1010{ }^{\circ} \mathrm{C}$ by $20 \mathrm{deg}$., the irreversible degradation of the Y123 structure takes place and the superconductive 

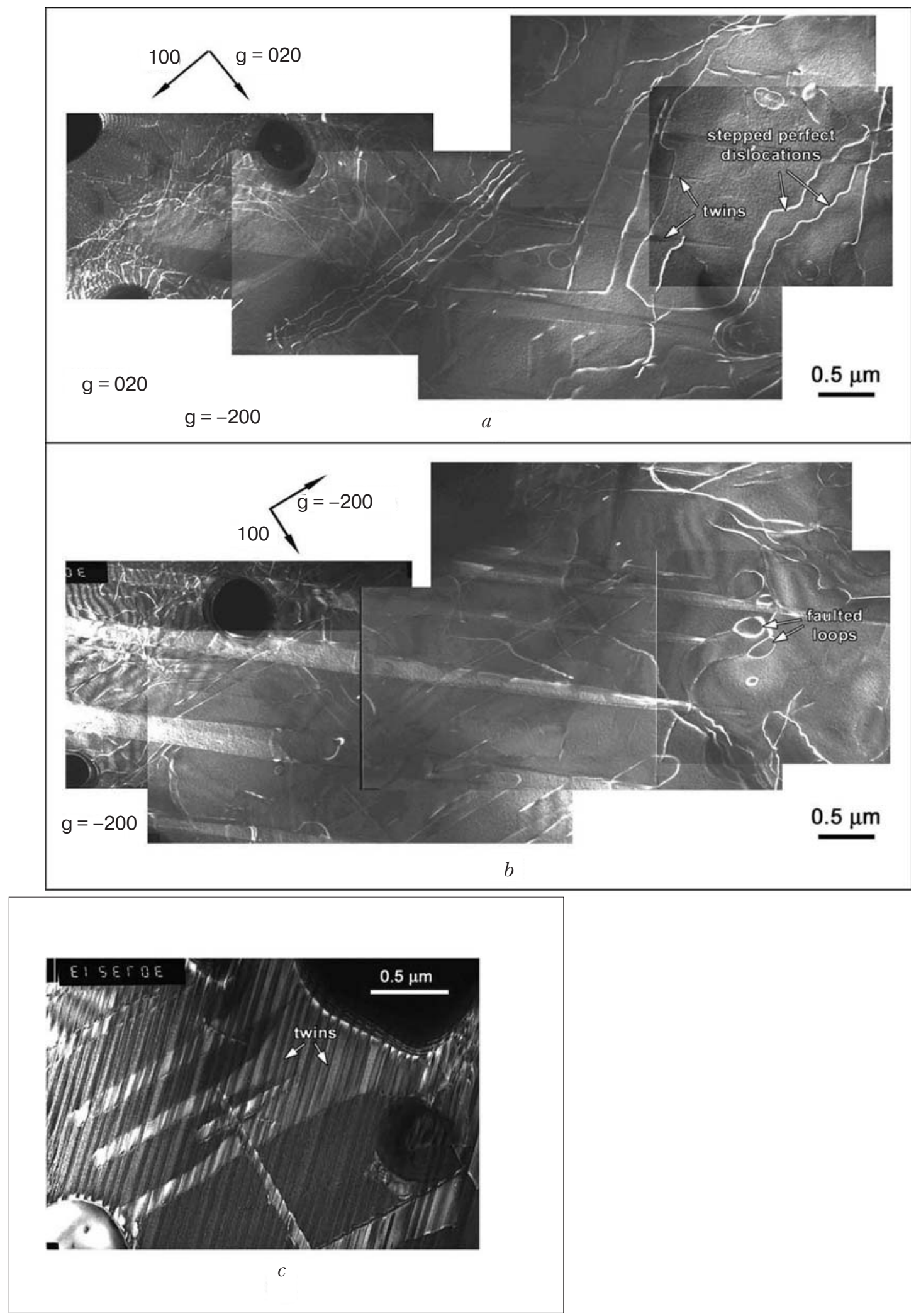

Fig. 8. TEM images show the low twin density, perfect dislocations stepped along $<110>$ directions and small faulted loops corresponding to $\mathrm{CuO}$ intercalating in the matrix of treated at 2GPa MT-YBCO; $(a)$, (b) TEM image of the structure of MT-YBCO oxygenated under $16 \mathrm{MPa}$ shows a high twin $\left(30 \mu \mathrm{m}^{-1}\right)$ and stacking fault density around Y211 inclusions $(c)$.

properties of Y123 structure could not be restored by repeated oxygenation, and a temperature of $980{ }^{\circ} \mathrm{C}$ is too low to form the superconducting junction with the high critical current density. If the holding time at 

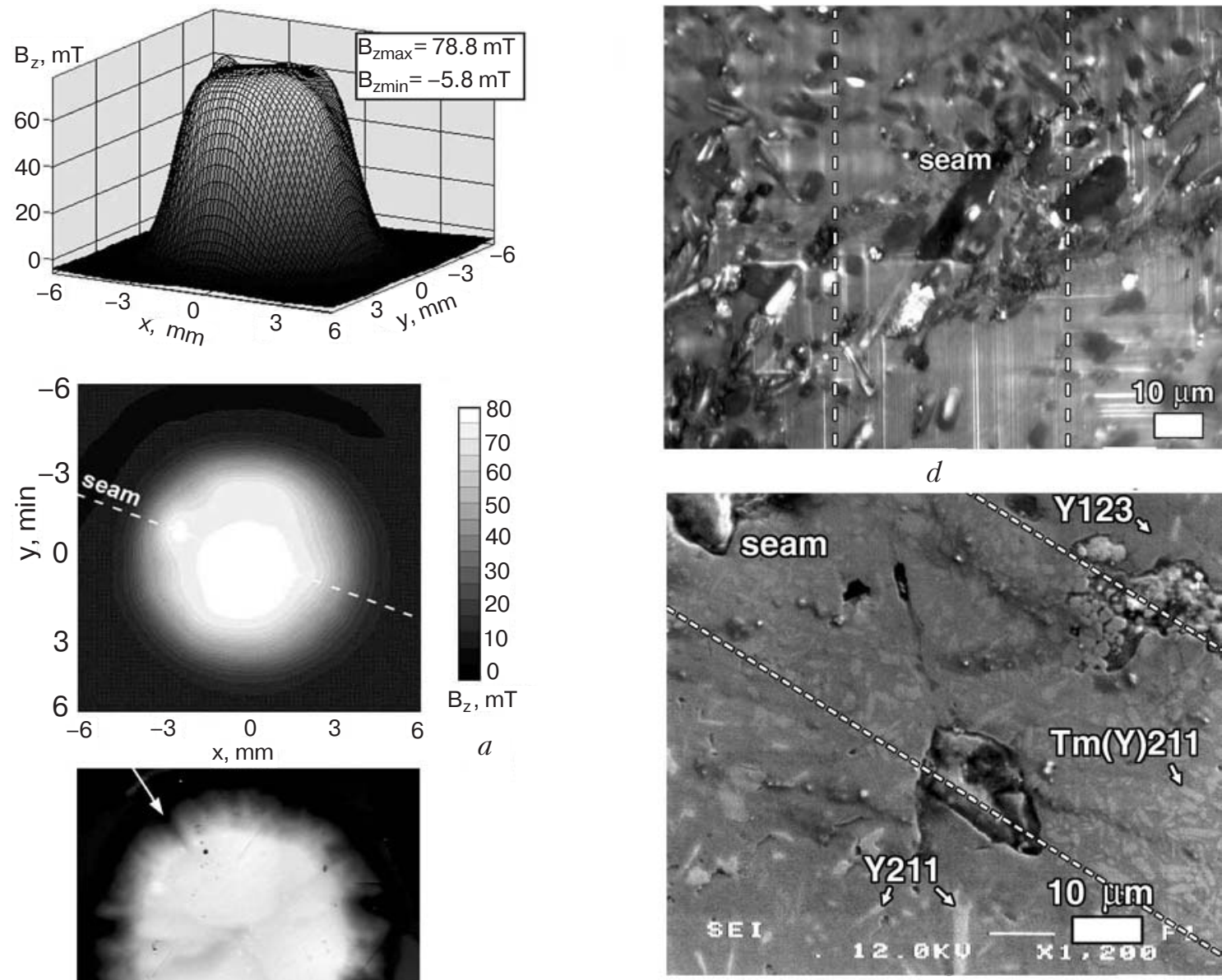

$e$

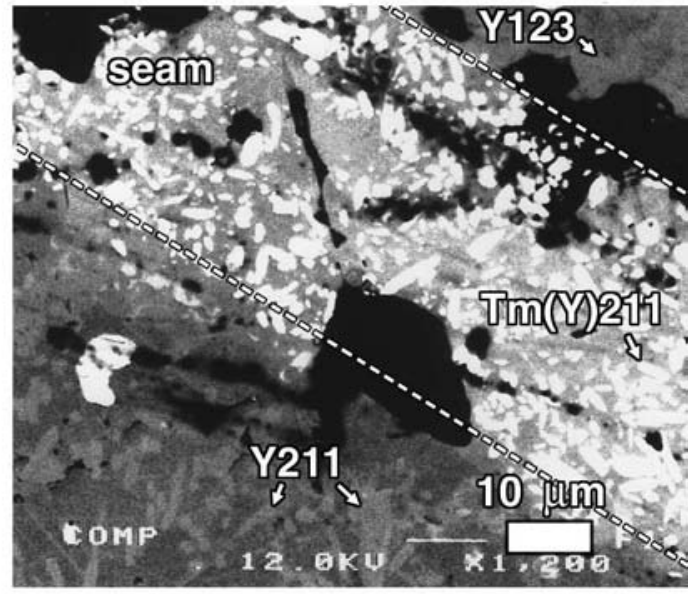

$f$

Fig. 9. Trapped-field map for the MT-YBCO ring $(\varnothing 8 \times 4 \mathrm{~mm}, h=4 \mathrm{~mm})$ joined by Tm123 powder. Regular shape of the truncated cone indicates that the trapped magnetic field is homogeneously distributed throughout the ring and that the critical current density in the seam is approximately the same as in the joined material $(a)$. Magneto-optical image of the same joined ring obtained at $61 \mathrm{~K}$. The brighter is the local area of the image, the larger is the local magnetic induction $(b)$. Critical current density $j_{c}$ vs. the magnetic field $\mu_{0} H(\mathrm{~T})$ of the same single-domain ring before cutting (curve 1), after cutting and soldering at $T=1010{ }^{\circ} \mathrm{C}$ (curve 2) and after cutting, soldering and oxygenation (curve 3). In the upper right corner the initial magnetization loops used for the jc calculation are given $(c)$. Microstructure of the soldered seam in the ring in: $(d)$-polarized light and $(e, f)$-obtained by SEM of the same place in different regimes: SEI $(e)$ and COMPO $(f)$.

$1000-1010{ }^{\circ} \mathrm{C}$ exceeds $15-20 \mathrm{~min}$, the coarsening of Y211 nonsuperconducting inclusions occurs in the place of junction formation (due to the recrystallization), which results in the decreasing of superconductive characteristics. In the case that the holding time is 30-40 min. at this temperature the continuous friable 
layer from the crystals of Y211 nonsuperconductive phase is formed and thus prevents the junction formation at all. The important technological parameters are heating and cooling rates, because during heating and cooling the oxygen content of superconductive Y123 phase varies, which induces the variation in superconductive properties of the material. The liberation and absorption of oxygen can lead to the material cracking and warping. When the junction is forming between single-domain MT-YBCO blocks without mackrocracks the heating rate can be rather high (up to $1000 \mathrm{deg} / \mathrm{h}$ ) and when the junctions are formed between blocks with imperfect structure containing several domains or mackrockracks, up to $600{ }^{\circ} \mathrm{C}$ the heating rate should not exceed $100 \mathrm{deg} / \mathrm{h}$, because such a rate will not lead to the formation of new cracks or to the broadening of the existing cracks and after the formation of junction the superconducting properties can be almost fully restored by repeated oxygenation. In order to avoid the crack formation during cooling, the reduction of temperature
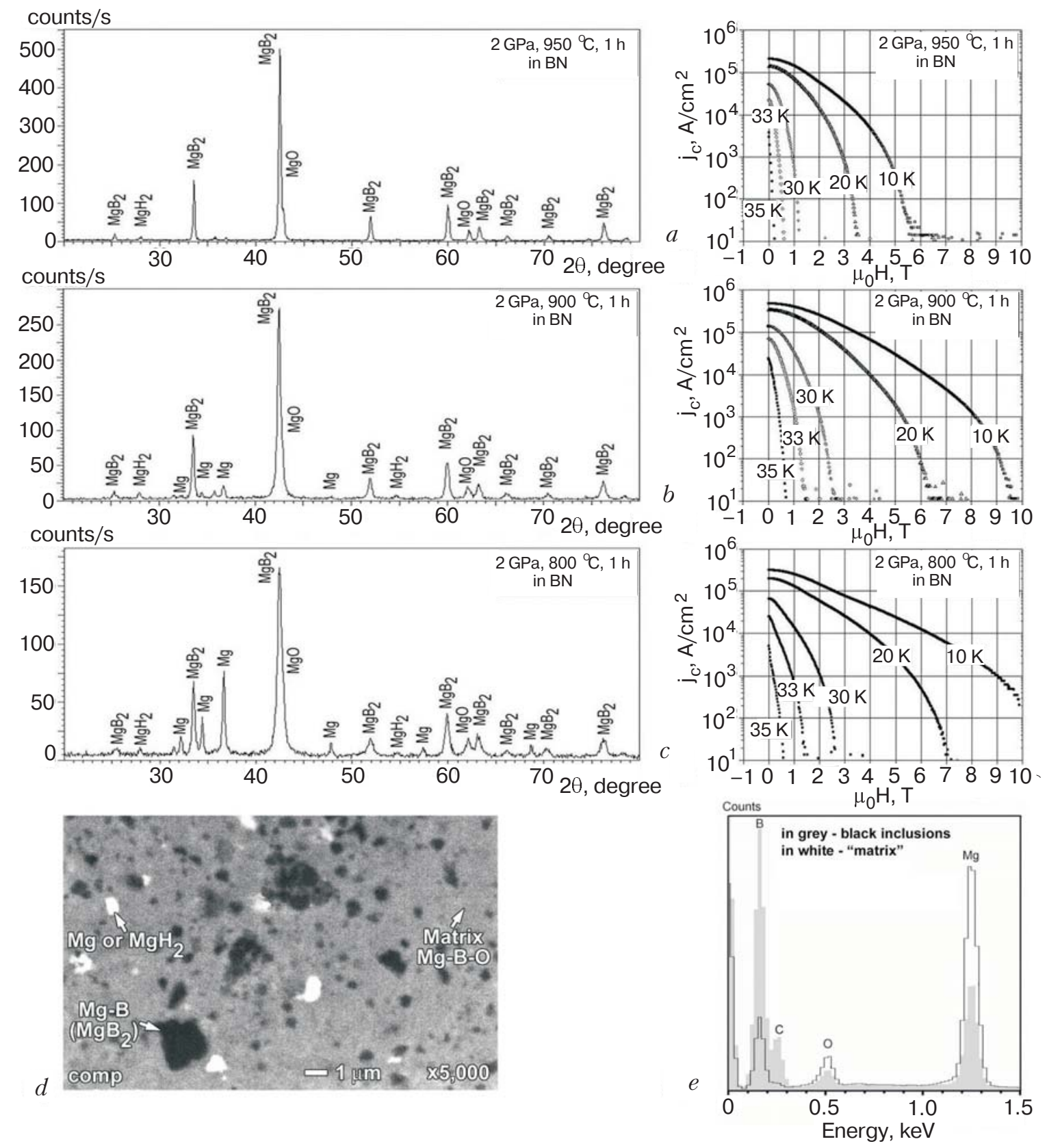

Fig. 10. X-ray patterns and critical current densities vs. magnetic field variation at different temperatures of the samples synthesized at $2 \mathrm{GPa}$ for $1 \mathrm{~h}$ from $\mathrm{Mg}$ and $\mathrm{B}$ (without additions) at 950,900 and $800{ }^{\circ} \mathrm{C}$, respectively $(a, b, c)$; backscattering electron image obtained by SEM of the sample synthesized from $\mathrm{Mg}$ and $\mathrm{B}$ at $2 \mathrm{GPa}$ and $800{ }^{\circ} \mathrm{C}$ for $1 \mathrm{~h}(d)$; energy-dispersive spectra of the sample shown in Fig. 10, $d$ : gray-colored spectrum is the spectrum of the «black» $\mathrm{Mg}-\mathrm{B}$ inclusions, white-colored spectrum is the spectrum of the «matrix» $\mathrm{Mg}-\mathrm{B}-\mathrm{O}$ phase of the sample $(e)$. 
should be rather quick (by switching off the furnace). The structure of superconductive seam with high characteristics (similar to those of the joined material) formed using a Tm123 solder is shown in Fig. 9,d,e. It is constituted from the $(\mathrm{Tm}, \mathrm{Y}) \mathrm{Ba}_{2} \mathrm{Cu}_{3} \mathrm{O}_{7-\delta}$ matrix with inclusions $(0.5-10 \mathrm{~mm})$ of the $(\mathrm{Tm}, \mathrm{Y})_{2} \mathrm{BaCuO}_{5}$ nonsuperconductive phase, is about $40-50 \mu \mathrm{m}$ thick and «repeats» the structure of the joined material (in the seam site, one can found inclusions of the $\mathrm{Tm}(\mathrm{Y}) 211$ phase of size corresponding to that of Y211 inclusions in the joined MT-YBCO (Fig. 9,f) and twin structure that continues the twin structure of the Y123 domains (Fig. 9,d)).

\section{High pressure-high temperature synthesis of highly dense nanostructural $\mathrm{MgB}_{2}$-based superconductive materials and elements for superconductive electricmotors and pumps}

In experiments on synthesis, metallic Mg chips (technical specifications of Ukraine 48-10-93-88) and amorphous B (of $1 \mu \mathrm{m}$, MaTecK, 95-97\% purity), were taken in the stoichiometric ratio of $\mathrm{MgB}_{2}$. To study the influence of $\mathrm{Zr}, \mathrm{Ti}$, Ta, or nano-SiC additions, the $\mathrm{Zr}$ (of 2-5 $\mu \mathrm{m}$, MaTecK, 94-98\% purity), Ti (of 1-3 $\mu \mathrm{m}$, MaTecK, 99\% purity), Ta (technical specifications 95-318-75, an average particle size of $1-3 \mu \mathrm{m}$ ) or nano-SiC $(20-30 \mathrm{~nm})$ powders were added to the stoichiometric $\mathrm{MgB}_{2}$ mixture of $\mathrm{Mg}$ and $\mathrm{B}$ in amounts of 2 or $10 \mathrm{wt} \%$. Components were mixed and milled in a high-speed activator with steel balls for 1-3 min. The resulting powder has been compacted into tablets. The x-ray study of the initial Mg, Ti, Ta, Zr, and B has shown that the materials contained no impurity phases with hydrogen (the accuracy of the method being about 3-5\%).

The structure of magnesium diboride samples high pressure-synthesized from $\mathrm{Mg}$ and $\mathrm{B}$, which in accordance with XRD analysis, contain mainly the $\mathrm{MgB}_{2}$ well-crystallized phase, has turned out to be more complicated as showed by SEM and microprobe examination [16] (Fig. 10). In parallel with $\mathrm{Mg}$ and $\mathrm{B}$ the nanostructure of the main «matrix» phase of the samples contains oxygen $(\mathrm{Mg}-\mathrm{B}-\mathrm{O})$ and is superconducting. $\mathrm{Mg}-\mathrm{B}$ (or most likely monocrystalline $\mathrm{MgB}_{2}$ ) inclusions of size from $10 \mu \mathrm{m}$ down to $200 \mathrm{~nm}$ or even smaller are distributed throughout the «matrix». Energy-dispersive analysis (Fig. 10,e) has shown that the amount of $\mathrm{Mg}$ in the «matrix» with respect to boron is much higher than is needed by the $\mathrm{MgB}_{2}$ stoichiometry, while the stoichiometry of «black» $\mathrm{Mg}-\mathrm{B}$ inclusions corresponds well to $\mathrm{MgB}_{2}$. Up to now it is not quite clear in what form oxygen is present in the nanostructural «matrix» of high pressure-synthesized magnesium diboride samples. The suggestion that $\mathrm{Mg}-\mathrm{B}$ inclusions are $\mathrm{MgB}_{2}$ single crystals is supported by the following facts:
(1) microprobe analysis shows that the amounts of $\mathrm{Mg}$ and $\mathrm{B}$ contained in such an inclusion are very close to the $\mathrm{MgB}_{2}$ stoichiometry and (2) nanohardness of these inclusions (estimated by a nanoindenter) at a $50 \mathrm{mN}$-load is $(35.6 \pm 0.9) \mathrm{GPa}$, which is higher than that of sapphire $((31.1 \pm 2.0) \mathrm{GPa})$, while nanohardness of the «matrix» is $(17.4 \pm 1.1) \mathrm{GPa}$ only. The Young moduli are $(213 \pm 18) \mathrm{GPa}$ of «matrix», $(385 \pm$ 14) $\mathrm{GPa}$ of the $\mathrm{Mg}-\mathrm{B}$ inclusion and (416 \pm 22$) \mathrm{GPa}$ of sapphire; (3) in many cases the inclusions are of a regular hexagonal shape.

Usually a higher amount of $\mathrm{Mg}-\mathrm{B}$ inclusions in the structure of high pressure-synthesized magnesium diboride corresponds to a higher critical current density and irreversibility field at $30-10 \mathrm{~K}$, in the so-called range of working parameters for $\mathrm{MgB}_{2}$ [16-18]. Samples, which are better from the point of view of SC characteristics, contain some amount of pure $\mathrm{Mg}$ and lesser amount of $\mathrm{MgH}_{2}$ impurity or this phase is absent at all. During high-pressure synthesis a source of hydrogen can be the cell of high-pressure apparatus: hydrogen may liberate from the materials (boron nitride, pyrophyllite, moisture, etc.) of the cell. As the synthesis temperature increases from $750-800{ }^{\circ} \mathrm{C}$ to $950{ }^{\circ} \mathrm{C}$, the amounts of $\mathrm{Mg}-\mathrm{B}$ inclusions and $\mathrm{MgH}_{2}$ impurity phase decrease. But the reduction of $\mathrm{Mg}-\mathrm{B}$ inclusions affects the decrease of $j_{c}$ more drastically than the reduction of $\mathrm{MgH}_{2}$ promotes its increase. In addition, we assume that impurity hydrogen may enter into the material structure decreasing the superconductive characteristics. Our findings have proved that hydrogen is harmful for critical current density in high pressure-synthesized $\mathrm{MgB}_{2}$ [16]. The structure of all high-pressure synthesized samples contains $\mathrm{MgO}$ in small proportion, which does not practically vary with the synthesis conditions.

A number of investigations have been performed to study a possibility to produce additional pinning centers in the $\mathrm{MgB}_{2}$ structure by chemical doping. Promising results have been obtained by adding $\mathrm{Ti}, \mathrm{Zr}$, and $\mathrm{SiC}$ [19-22]. It was shown by us that addition of Ta positively influences superconductive properties of high-pressure synthesized and sintered $\mathrm{MgB}_{2}$ [17]. The investigation of the $\mathrm{Ti}$ and $\mathrm{Zr}$-doped high pressure-synthesized magnesium diboride has allowed us to reveal the mechanism of the Ti and $\mathrm{Zr}$ influence on superconductive properties absolutely different from the one proposed for magnesium diboride synthesized at ambient pressure. In the case of $\mathrm{Ti}$ or $\mathrm{Zr}$, and high-pressure synthesis it is similar to that shown by us for Ta additions [18].

Figure 11, $a-e$ demonstrate the results of the study of high-pressure synthesized (HPS) $\mathrm{MgB}_{2}$ with additions of nano-SiC, $\mathrm{Ti}$, and $\mathrm{Zr}$, while Fig. 11, f shows the results of the quantitative investigation of the amount of «black» $\mathrm{Mg}-\mathrm{B}$ (or $\mathrm{MgB}_{2}$ ) inclusions and $j_{c}$ of the 

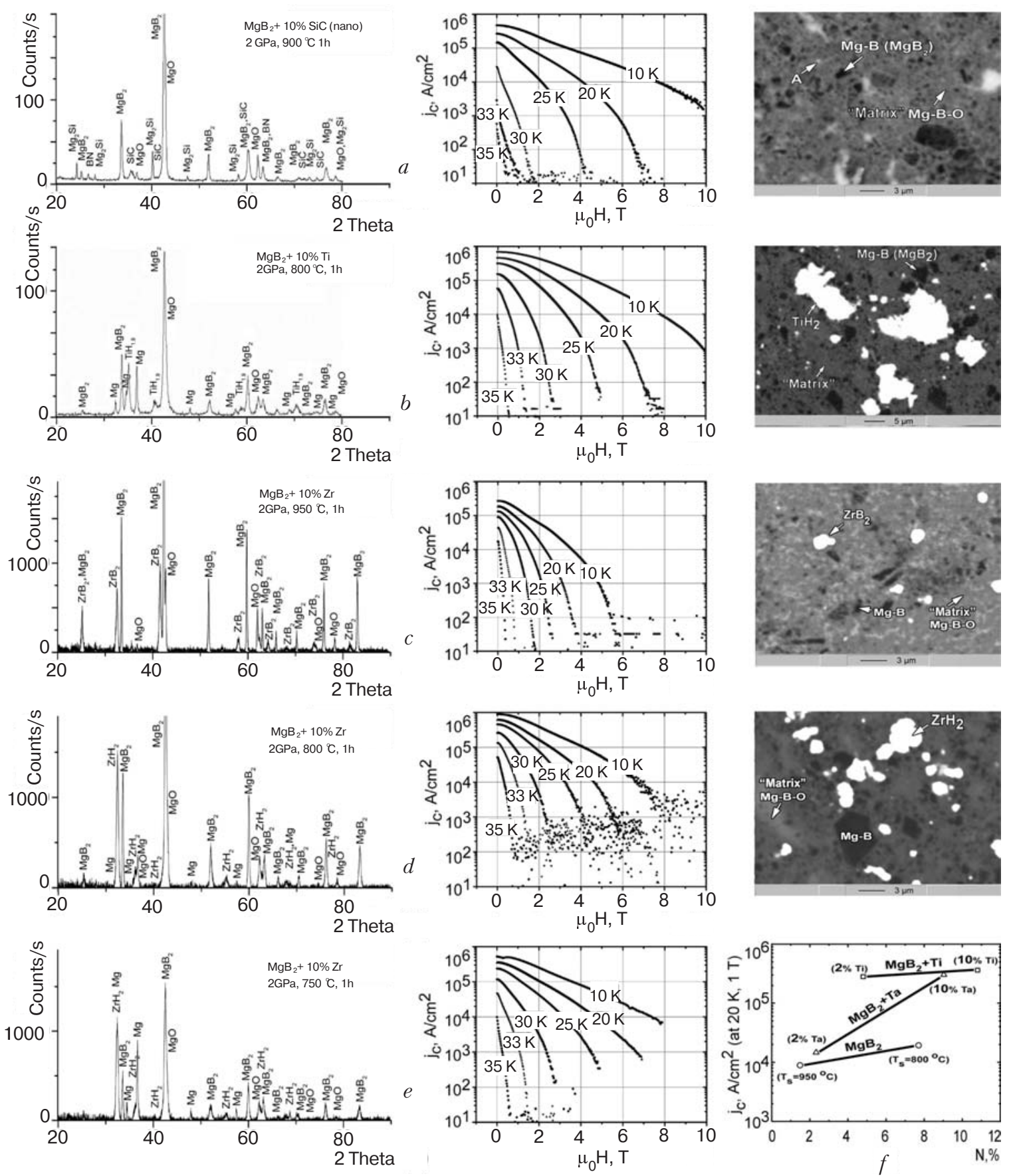

Fig. 11. X-ray patterns, dependences of $j_{c}$ on magnetic fields, $\mu H$, and structure obtained by SEM in backscattering electron image of the HPS- $\mathrm{MgB}_{2}$ with additions of $\mathrm{SiC}$, $\mathrm{Ti}$, and $\mathrm{Zr}$. (Regimes of synthesis and amount of additions are given in the pictures.) The $j_{c}$ vs. amount of «black» $\mathrm{Mg}-\mathrm{B}$ inclusions, $\mathrm{N}$, for HPS-MgB2 samples without additions and with additions of $\mathrm{Ta}$ and $\mathrm{Ti}$ ( $\mathrm{N}, \%$, was calculated as a ratio of the area that is occupied by «black» inclusions in the image of the structure obtained at $1600 \times$ magnification to the total area of the image obtained by SEM in the backscattering electron regime) $(f)$.

HPS $\mathrm{MgB}_{2}$ samples without additions and with additions of Ta and Ti. All the additions under study induce an improvement of $j_{c}$ in HPS $\mathrm{MgB}_{2}$. Figure 12 summarizes the dependences of critical current density $j_{c}$ on magnetic field $\left(\mu_{0} H, \mathrm{~T}\right)$ of HPS $\mathrm{MgB}_{2}$ with and without additions of Ta, Ti, Zr, and nano-SiC at 10, 20, and $30 \mathrm{~K}$ (the best data for each field is given irrespective of the amount of addition and regime of synthesis). The most pronounced improvement of $j_{c}$ is observed when $\mathrm{Ti}$ and $\mathrm{Zr}$ are added. The addition of nano-SiC increases the $j_{c}$ value at $10 \mathrm{~K}$ in the fields higher than $8 \mathrm{~T}$. Usually the improvement in critical current density in the case that $\mathrm{Ti}$ or $\mathrm{Zr}$ are added to the materials synthesized at ambient pressure is explained by the formation 

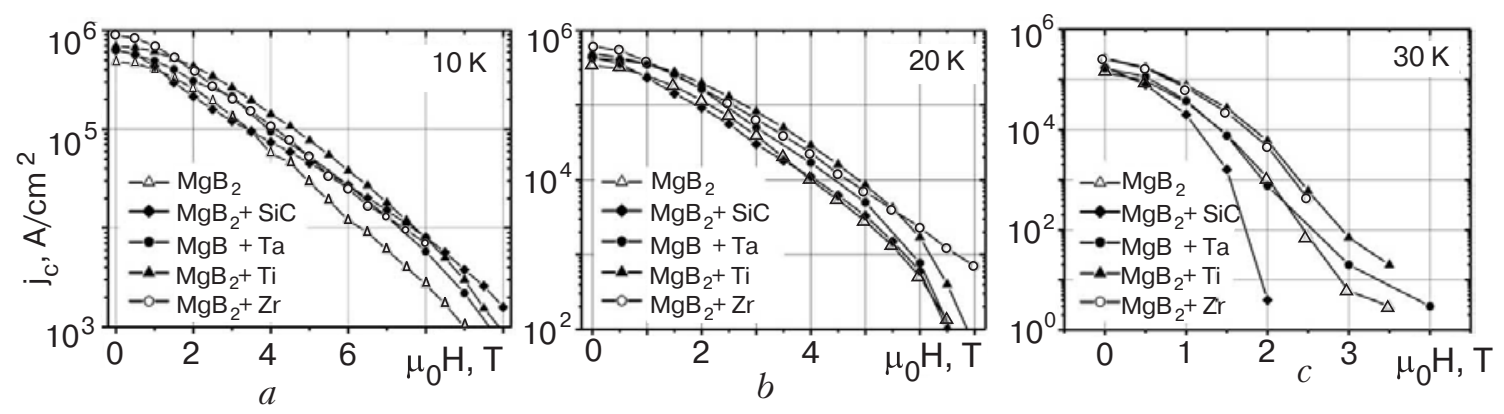

Fig. 12. Generalized dependences of $j_{c}$ on $\mu_{0} H$ for $\mathrm{MgB}_{2}$ without and with additions of $\mathrm{Ta}, \mathrm{Ti}, \mathrm{Zr}$, nano-SiC at different temperature $T, \mathrm{~K}: 10(a), 20(b), 30(c)$.

of the $\mathrm{TiB}_{2}$ or $\mathrm{ZrB}_{2}$ thin layers at grain boundaries that increase the number of pinning centers, which is ascribed to a $j_{c}$ improvement caused by doping with these elements [22]. The main effect of $\mathrm{Ti}, \mathrm{Zr}$ and $\mathrm{Ta}$ in all cases for HPS $\mathrm{MgB}_{2}$ can be explained by the absorption of impurity hydrogen to form $\mathrm{TiH}_{1.94}, \mathrm{ZrH}_{2}$ or $\mathrm{Ta}_{2} \mathrm{H}$. Additions of $\mathrm{Zr}$, Ti or Ta can prevent the harmful (for $j_{c}$ ) $\mathrm{MgH}_{2}$ impurity phase from appearing and hydrogen from being introduced into the material structure. Contrary to the data from literature the appearance of $\mathrm{ZrB}_{2}$ (at synthesis temperature $T_{S}=950$ ${ }^{\circ} \mathrm{C}$, Fig. 11,c) does not affect the $j_{c}$ of $\mathrm{HPS} \mathrm{MgB}_{2}$.

XRD evidence (Fig. 11,b) suggests that the only titanium-containing compound in this material is a titanium hydride compound, $\mathrm{TiH}_{1.924}$, EDX measurements support this result since the only detectable element present in the titanium-rich regions is titanium as such (hydrogen is not detectable by EDX analysis). The presence of $\mathrm{TiH}_{1.924}$ has been a surprise since titanium hydrides are relatively unstable compared to the more common titanium compounds, particularly the oxide phases for which we expect the constituent elements to be readily available in these impure ceramics. Enthalpy of formation values illustrating the relatively low stability of this titanium hydride is given in Table 2 [23].

Then the high-pressure synthesized magnesium diboride sample with $10 \%$ of Ti additions was finely ground and the particle that according to EDX study contained Ti only was removed and subjected to the TEM investigation (Fig. 14). A transmission electron diffraction pattern (TED) taken from this particle was compared with the standard $d$-spacings from the JC-PDS database and shown that the ratio of rings in this pattern corresponded closely with those predicted for titanium hydride $\mathrm{TiH}_{1.924}$, and does not match very well with any of the other $\mathrm{Ti}$ compounds in Table 2 [23].
Table 2. Table comparing enthalpies of formation values for a range of common Ti compound [23].

\begin{tabular}{c|c}
\hline \hline Compound & Enthalpy of formation $\left(\mathrm{kJ} \cdot \mathrm{mol}^{-1}\right)$ \\
\hline \hline $\mathrm{Ti}_{3} \mathrm{O}_{5}$ & -1520.9 \\
$\mathrm{Ti}_{2} \mathrm{O}_{3}$ & -944.057 \\
$\mathrm{TiO}_{2}$ & -336.6 \\
$\mathrm{TiN}$ & -150 to -314 \\
$\mathrm{TiB}_{2}$ & -15.0 \\
$\mathrm{TiH}_{2}$ & \\
\hline \hline
\end{tabular}

Figure 13 shows nanoSIMS ion maps of the distribution of hydrogen, boron and magnesium ions and ${ }^{48} \mathrm{Ti}^{1} \mathrm{H}^{-}$ion clusters from a region of the $\mathrm{MgB}_{2}$ matrix containing a number of titanium-rich particles. The detection of ${ }^{48} \mathrm{Ti}^{1} \mathrm{H}^{-}$ions demonstrates a close association between hydrogen and titanium in these particles. It is also clear that the yield of hydrogen is much greater from the titanium-rich particles than from the surrounding matrix. In order to discount the possibility that this effect is caused by an enhanced yield of $\mathrm{H}$ from the vacuum system condensing on the surface of metallic $\mathrm{Ti}$, we have analyzed the $\mathrm{H}$ yield from a bulk Ti metal standard under the same instrumental conditions. In this experiment the number of counts/second detected at mass 1 is at least 100 times lower than from the Ti-rich particles in the $\mathrm{MgB}_{2}$ sample. We consider this new TED and SIMS data as being very strong supporting evidence for the presence of $\mathrm{TiH}_{1.924}$ in the high-pressure synthesized $\mathrm{MgB}_{2}$ with $\mathrm{Ti}$ added. It allows us to suggest that one reason for the improvement in the measured properties of the Ti-doped material as compared to similar $\mathrm{MgB}_{2}$ materials without additions may be that hydrogen is a deleterious impurity in the matrix which can be absorbed by the titanium particles. The reducing conditions created by free hydrogen under the high-pressure condi- 


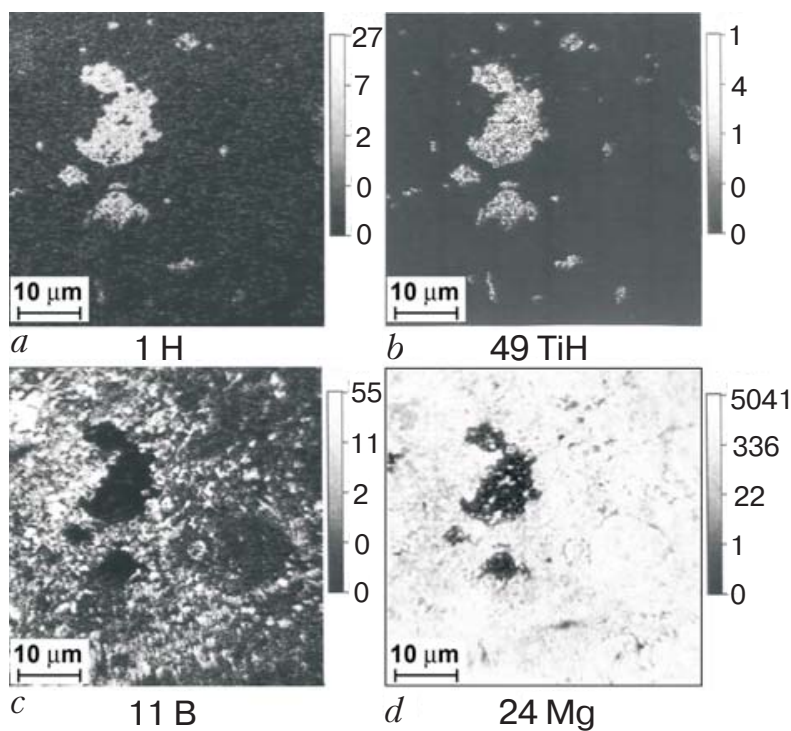

Fig. 13. NanoSIMS ion maps of the distribution of $(a)$ mass $1 \mathrm{H}^{-},(b)$ mass $11 \mathrm{~B},(c)$ mass $49 \mathrm{TiH}^{-},(d)$ mass 24 $\mathrm{Mg}^{-}$in high pressure synthesized $\mathrm{MgB}_{2}$ material with the $10 \mathrm{wt} \%$ Ti addition.

tions could explain why the much more stable Ti oxide compounds are not formed.

A decrease in the synthesis temperature, $T_{S}$, results in an increase of the amount of $\mathrm{Mg}-\mathrm{B}$ inclusions and an increase in the amount of $\mathrm{Ti}$ or Ta provokes the increase in the amount of these inclusions as well (Fig. 11,f). The correlation between the amount of $\mathrm{Mg}-\mathrm{B}$ inclusions and increase of $j_{c}$ is not so strict because several factors affect the $j_{c}$. For example, a decrease in the $\mathrm{T}_{\mathrm{s}}$ results in an increase of $\mathrm{MgH}_{2}$ phase formation (harmful to $j_{c}$ ) and in an increase of the amount of free $\mathrm{Mg}$ and $\mathrm{Mg}-\mathrm{B}$ inclusions that positively affect $j_{c}$. Besides, a decrease in the $T_{s}$ can leads to a decrease in the material density. But many observations allow us to conclude that $j_{c}$ is most strongly influenced by the amount of $\mathrm{Mg}-\mathrm{B}$ inclusions.

The highest $j_{\mathrm{c}}$ for HPS $\mathrm{MgB}_{2}$ with nano-SiC additions was observed at $T_{S}=900{ }^{\circ} \mathrm{C}$. $\mathrm{SiC}$ does not absorb hydrogen and at low $T_{S}\left(750-800{ }^{\circ} \mathrm{C}\right)$ in the HPS $\mathrm{MgB}_{2}$, the $\mathrm{MgH}_{2}$ phase forms and hydrogen probably enters into the material structure decreasing the $j_{c}$. At higher $T_{s}\left(900{ }^{\circ} \mathrm{C}\right)$ hydrogen seems to be partly liberated from the pressure cell during the synthesis and the grains $« \mathrm{~A} »$ containing $\mathrm{Si}, \mathrm{C}, \mathrm{Mg}, \mathrm{B}$ or $\mathrm{Mg}_{2} \mathrm{Si}$ and $\mathrm{SiC}$ found by x-ray (Fig. 1,a) may serve as pinning centers (instead of $\mathrm{Mg}-\mathrm{B}$ inclusions, whose amount decreases at such $T_{s}$ ). We do not rule out the opinion as to $\mathrm{MgB}_{2}$ with nano-SiC addition synthesized under ambient pressure that $\mathrm{SiC}$ may be incorporated into the $\mathrm{MgB}_{2}$ lattice and thus facilitate the intragrain pinning.

The hardness of the HPS material (HPS $\mathrm{MgB}_{2}$ with $10 \% \mathrm{Ta}$ ) measured by a Vickers indenter under a
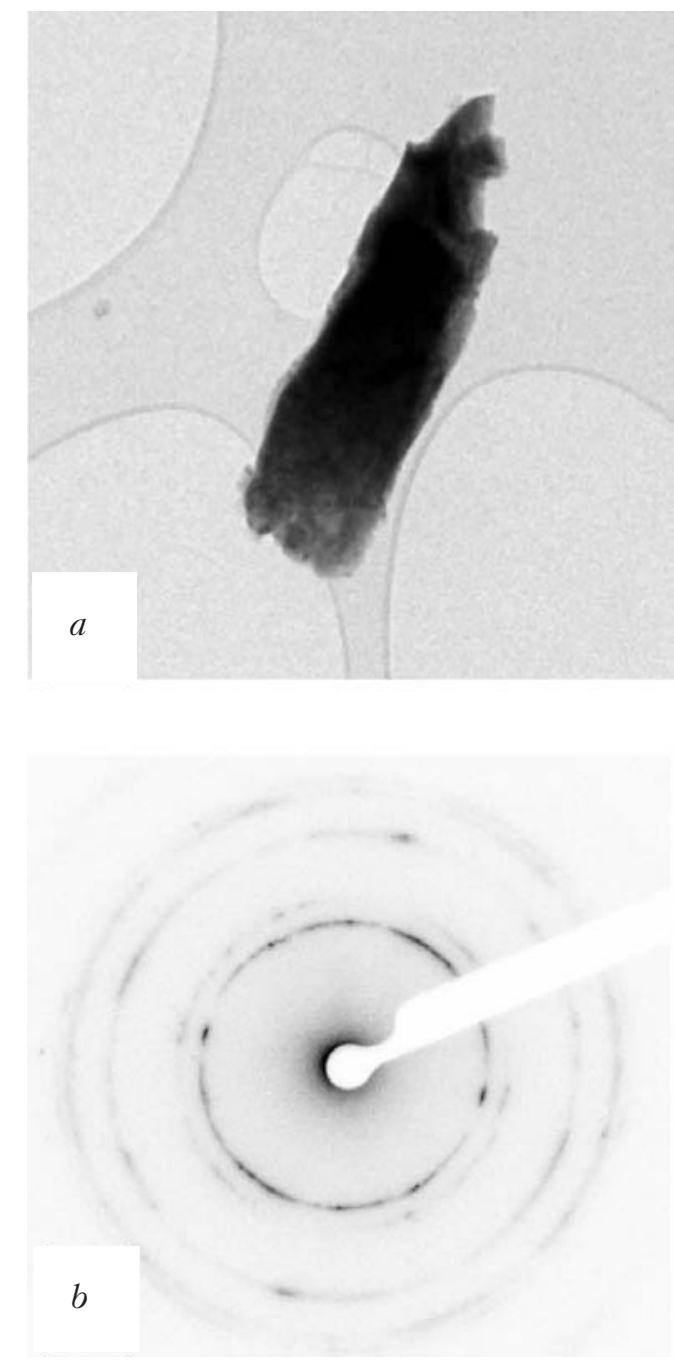

Fig. 14. (a) Bright-field TEM image of a particle from the powdered sample of the high pressure synthesized $\mathrm{MgB}_{2}$ material with $10 \mathrm{vol} \% \mathrm{Ti}$ addition. (b) electron diffraction pattern contrast inverted from the Ti-rich particle shown in $(a)$.

load of $148,8 \mathrm{~N}$ is $H_{V}=(10,12 \pm 0,2) \mathrm{GPa}$ and the fracture toughness under the same load is $K_{1 C}=$ $=(7,6 \pm 2,0) \mathrm{MPam}^{0.5}$. The HPS $\mathrm{MgB}_{2}$ without additions has $H_{V}=(16,85 \pm 0,74) \mathrm{GPa}$ and $K_{1 C}=$ $=(4,24 \pm 0,14) \mathrm{MPam}^{0.5}$ under a 4,96 N-load.

Highly dense alloyed HPS $\mathrm{MgB}_{2}$ shows $j_{\mathrm{c}}$ at $20 \mathrm{~K}$ higher than $10^{5} \mathrm{~A} / \mathrm{cm}^{2}$ up to $3 \mathrm{~T}, 10^{4} \mathrm{~A} / \mathrm{cm}^{2}$ up to $5 \mathrm{~T}$ and $10^{3}$ up to $7 \mathrm{~T}$ fields and high mechanical characteristics.

Using the proposed method the cylindrical (up to $32 \mathrm{~mm}$ in diameter and $20 \mathrm{~mm}$ in height), quadratic $(25 \times 25 \times 4 \mathrm{~mm})$ and rectangular $(25 \times 18 \times 4)$ plates can be high-pressure synthesized. The method of highpressure high-temperature synthesis of rectangular and quadratic plates has been developed in accordance with the requirements for rotor in order to minimize the cutting and grinding highly dense and hard 
$\mathrm{MgB}_{2}$ - based ceramics. In the case of thin $(4 \mathrm{~mm})$ plates several samples can be synthesized in one run in the same high pressure apparatus.

Recently the big ring $\left(D_{1} \times D_{2} \times l=56 \times 58 \times 25 \mathrm{~mm}\right)$ from $\mathrm{MgB}_{2}$ (with additions of $\mathrm{Ti}$ ) has been synthesized under 1 atm $\mathrm{Ar}$ pressure from the preliminarily high-pressure compacted initial mixture of $\mathrm{Mg}, \mathrm{B}$, and Ti powders. The results of calculations based on the estimated critical current density of the synthesized ring (that was $16 \mathrm{kA} / \mathrm{cm}^{2}$ at $10 \mathrm{~K}$ and $8 \mathrm{kA} / \mathrm{cm}^{2}$ at $20 \mathrm{~K}$ ) shown that the ring can trap $1.8 \mathrm{~T}$ magnetic field at $10 \mathrm{~K}$.

In February 2005 the first in the world superconductive motor with rotor contained layers of magnesium diboride high-pressure high-temperature synthesized at the Institute for Superhard Materials (by the team of T. Prikhna) was successfully tested at the Moscow Aviation Institute (MAI). The motor was developed and constructed by the teams of Prof. L.K. Kovalev (MAI) and Prof. W. Gawalek (Institute für Physikalische Hochtechnologie, Jena, Germany). The comparative tests of the motors with $\mathrm{MgB}_{2^{-}}$and MT-YBCO-based rotors have shown that the motor have similar operating characteristics at $20 \mathrm{~K}$.

\section{Conclusions}

The developed processes of high pressure-high temperature synthesis, sintering and densification of superconductive ceramic materials, processes of soldering and oxygenation are rather promising for preparation of materials for cryogenic machines and devices working on principals of levitation at nitrogen and hydrogen temperatures.

1. L.K. Kovalev , K.V. Ilushin, K.L. Kovalev et al., Physica C386, 419 (2003).

2. Handbook of Superconducting Materials, Vol. 1: Superconductivity, Materials and Processes, Davi A. Cardwell, David S. Ginley (eds.) IoP, Institute of Physics Publishing, Bristol and Philadelphia (2003), p. 927.

3. C. Buzea and T. Yamashita, Supercond. Sci. Technol. 14, 115 (2001).

4. T.A. Prikhna, J. Rabier, A. Proult et al., Supercond. Sci. Technol. 17, 515 (2004).

5. Declaration Patent of Ukraine No 68888 A., The Superconductive Material, T.A. Prikhna, W. Gavalek, N.V. Novikov et al. Priority from November 14 (2003), published in Bull. No 8, 16.08.2004.

6. K.Tanaka, J. Mater Sci. 22, 1501 (1987).

7. T.A. Prikhna, V.S. Melnikov, V.V. Kovylyaev, and V.E. Moshchil, J. Mat. Sci. 30, 3662 (1995).

8. T. Prikhna, W. Gawalek, V. Moshchil, S. Dub, V. Melnikov, A. Surzhenko, P. Nagorny, N. Sergienko, F. Sandiumenge, and P. Schaetzle, Physica C354, 415 (2001).
9. T. Prikhna, W. Gawalek, V. Moshchil, S. Dub, T. Habisreuther, V. Melnikov, F. Sandiumenge, V. Kovylaev, A. Surzhenko, P. Nagorny, P. Schaetzle, A. Borimsky, 2000 Functional Materials (EUROMAT-99) K. Grassie, E. Teuckhoff, G. Wegner, J. Hausselt, H. Hanselka (eds.) 13, p. 153.

10. T.A. Prikhna, W. Gawalek, F. Sandiumenge, V.E. Moshchil, V.S. Melnikov, S.N. Dub, T. Habisreuther, A.B. Surzhenko, and P.A. Nagorny, J. Mat. Sci. 35, 1607 (2000).

11. T.A. Prikhna, J. Rabier, A. Proult, X. Chaud, W. Gawalek, A.V. Vlasenko, J.-L. Soubeyroux, R. Tournier, F. Sandiumenge, Ya.M. Savchuk, V.E. Moshchil, P.A. Nagorny, N.V. Sergienko, V.S. Melnikov, S. Kracunovska, D. Litzkendorf, and S.N. Dub, Supercond. Sci. Technol. 17, S1 (2004).

12. Patent of Ukraine 49564 A (B22F3/14, C04B35/00) The Method of Supeconducting Junction Formation between Blocks of Melt-textured $\mathrm{YBa}_{2} \mathrm{Cu}_{3} \mathrm{O}_{7-\delta}$-based ceramics (MT-YBCO), T.A. Prikhna, W. Gawalek, N.V. Novikov, et al., published in Bull. No 9, 16.09.2002.

13. Declaration Patent of Ukraine 55212 A (H03B15, B22F3/14, C04B35/00) The Method of Superconducting Junction Formation between Elements of Melt-textured $\mathrm{YBa}_{2} \mathrm{Cu}_{3} \mathrm{O}_{7-\delta}$-based ceramics (MT-YBCO), T.A. Prikhna, W. Gawalek, N.V. Novikov, et al., published in Bul. No 3, 17.03.2003.

14. T.A. Prikhna, W. Gawalek, V.E. Moshchil, N.V. Sergienko, V.B. Sverdun, A.B. Surzhenko, L.S. Uspenskaya, R. Viznichenko, A.A. Kordyuk, D. Litzkendorf, T. Habisreuther, S. Kracunovska, and A.V. Vlasenko, Supercond. Sci. Technol. 18, 153 (2005).

15. Patent of Ukraine 37848 A (G01R33/035 - № 2000042336) The Method of Determination of Critical Current Density in Superconductors, V.V. Nemoshkalenko, A..A. Korduk, A.I. Plushchay et al. priority from 24.04.2000, published in Bull. No 415.05.2001.

16. T.A. Prikhna, W. Gawalek, Ya.M. Savchuk, V.E. Moshchil, N.V. Sergienko, T. Habisreuther , M. Wendt, R. Hergt, Ch. Schmidt, J..Dellith, V.S. Melnikov, A. Assmann, D. Litzkendorf, and P.A. Nagorny, Physica C: Superconductivity 402, 223 (2004).

17. T.A. Prikhna, W. Gawalek, Ya.M. Savchuk, V.E. Moshchil, N.V. Sergienko, A.B. Surzhenko, M. Wendt, S.N.Dub, V.S. Melnikov, Ch. Schmidt, and P.A. Nagorny, Physica C386, 565 (2003).

18. T.A. Prikhna, W. Gawalek, Ya.M. Savchuk, N.V. Sergienko, V.E. Moshchil, S.N. Dub, M.Wendt, V.S. Melnikov, A.B. Surzhenko, D. Litzkendorf, P.A. Nagorny, and Ch. Schmidt, Proc. Int. Conf. on Science for Material in the Frontier of Centuries: Advantages and Challenges, 4-8 November 2002, Kyiv, Ukraine (2002), p. 406.

19. S. Soltanian, X. Wang, J. Horvat, M. Qin, H. Liu, P.G. Munroe, and S.X. Dou, IEEE Trans. Appl. Supercond. 13, 3273 (2003).

20. Y. Zhao, Y. Feng, C.H. Cheng, L. Zhao, Y. Wu, T. Machi, Y. Fudamoto, N. Koshizuka, and M. Murakami, Appl. Phys. Lett. 79, 1154 (2001). 
21. Y. Feng, Y. Zhao, P. Sun, F.C. Liu, B.Q. Fu, L. Zhou, C.H. Cheng, N. Koshizuka, and M. Murakami, Appl. Phys. Lett. 79, 3983 (2001).

22. D. Goto, T. Machi, Y. Zhao, N. Koshizuka, M. Murakami, and S. Arai, Physica C 392-396, 272 (2003).
23. S. Haigh, P. Kovac, T.A. Prikhna, Ya.M Savchuk, M. Kilburn, C. Salter , J. Hutchison, and C. Grovenor, Supercond. Sci. Technol. 18, 1 2005). 